\title{
The Shadow of the Consumer: Analyzing the Importance of Consumers to the Uptake and Sophistication of Ratings, Certifications, and Eco-Labels
}

Organization \& Environment 2020, Vol. 33(I) 75-95 (C) The Author(s) 2018 Article reuse guidelines: sagepub.com/journals-permissions DOI: $10.1177 / 10860266 / 8803748$ journals.sagepub.com/home/oae

$\Theta$ SAGE

\author{
Graham Bullock ${ }^{1 *}$ and Hamish van der Ven ${ }^{2 *}$
}

\begin{abstract}
Why has the market uptake and sophistication of information-based environmental governance (IBEG) programs like eco-labeling increased despite mixed signals on the willingness and ability of individual consumers to support such programs? We argue that the extant literature on IBEG focuses too narrowly on individual consumer purchasing decisions to the exclusion of other mechanisms through which consumers, both as individuals and as an imagined collective, exert influence. As a corrective, we present a novel conceptual framework that highlights the different causal mechanisms through which consumers contribute to the uptake and sophistication of IBEG. We call our framework "the shadow of the consumer" since it suggests a more latent and indirect role for consumers than voting-with-one's-wallet. Our analysis adds nuance and complexity to accounts of consumer agency vis-à-vis environmental ratings, standards, certifications, and eco-labels and helps explain the proliferation and growing sophistication of such programs despite the variability of individual consumer support.
\end{abstract}

\section{Keywords}

ratings, certifications, standards, eco-labels, consumers, information-based environmental governance, corporate social responsibility

\section{Introduction}

Sustainability ratings, voluntary standards, certifications, and eco-labels are examples of a broader phenomenon often referred to as information-based environmental governance (IBEG) (Bullock, 2016, 2017). Recent years have witnessed two broad trends in IBEG. The first is the growing market uptake of IBEG programs. Third-party eco-labels, sustainability standards, and certifications continue to undergo "exceptional growth" in nearly every commercial sector (Lernoud et al., 2017, p. 3; Potts, Lynch, Wilkings, Cunningham, \& Voora, 2014). Certified

\footnotetext{
'Davidson College, Davidson, NC, USA

2McGill University, Montreal, QC, Canada

*The authors contributed equally to this article.

\section{Corresponding Author:}

Hamish van der Ven, McGill University, Leacock Building, Room 4I4, 855 Sherbrooke Street West, Montreal, Québec H3A 2T7, Canada.

Email: hamish.vanderven@mcgill.ca
} 
organic farmland has increased from less than a million acres in 1992 to over 5 million in 2011 (USDA Economic Research Service, 2013), ENERGY STAR has certified 87 billion square feet of commercial space in the United States (ENERGY STAR, n.d.), and 25\% of global coffee production is now compliant with at least one sustainability standard (Lernoud et al., 2017). Across sectors and regions, IBEG is increasingly moving from the margins to the mainstream of global markets (Tayleur et al., 2017).

The second trend is the growing sophistication of IBEG programs as they increasingly come to resemble more conventionally "public" forms of global governance in their efforts to engage diverse stakeholders, ensure transparency, and improve the rigor and credibility of their efforts to "green" the market (Bernstein, 2014; van der Ven, 2015). Elaborate forms of metagovernance in the form of best practice guidelines (i.e., the ISEAL Codes) have emerged to systematize the procedures through which environmental standard setters establish, audit, and evaluate their programs (Bernstein \& van der Ven, 2017; Derkx \& Glasbergen, 2014). While many weaknesses remain in the substantive content of IBEG systems (Loconto \& Fouilleux, 2014) - that is, the criteria by which eco-labels are awarded and ratings are calculated - the procedures through which IBEG systems are created and maintained have become much more rigorous since the first eco-labels emerged in the 1970s (Fouilleux \& Loconto, 2017; Loconto \& Fouilleux, 2014). In tandem with market mainstreaming, this is an important development in the ability of IBEG programs to generate desirable environmental outcomes (Fransen, 2011; Kalfagianni \& Fuchs, 2015).

In light of these dual trends, one may reasonably inquire about the role of individual consumers in fomenting the growth and sophistication of IBEG. The multidisciplinary literature on IBEG-which includes work from political science, law, sociology, behavioral economics, social psychology, strategic management, and business ethics-reaches two divergent conclusions on this question. On one hand, some research suggests that consumers have been more responsive to IBEG than many assume, and cites evidence of increasing recognition and sales of labeled products (Conroy, 2007; Hartman Group, 2017; Teisl, Roe, \& Hicks, 2002). It also suggests that consumers may become even more engaged if these programs are designed and communicated more thoughtfully and strategically than in the past (Marette, Messéan, \& Millet, 2012). On the other hand, IBEG is often presented as too uncertain, complex and confusing for the general public to understand and effectively utilize (Akenji, 2014; Harbaugh, Maxwell, \& Roussillon, 2011). The proliferation of IBEG programs making superficially similar claims renders it difficult for consumers to distinguish "greenwash" from the more credible and sophisticated programs (Ben \& Abderrazak, 2009; Brécard, 2017; Heyes \& Martin, 2016). Even if people do manage to recognize credible IBEG, consumer willingness to pay for products identified as "greener" or more responsible is highly variable (Hainmueller, Hiscox, \& Sequeira, 2014; Hidrue, Parsons, Kempton, \& Gardner, 2011).

Given the decidedly mixed evidence in support of the hypothesis that individual consumers are driving the market uptake and increasing sophistication of IBEG through their purchasing decisions, we propose a different account. Our main argument is that consumers do indeed contribute to the uptake and sophistication of IBEG, but often less directly than commonly assumed. We advance the concept of the "shadow of the consumer" to illustrate the numerous interconnected pathways through which consumers indirectly exert influence over IBEG outside of their direct spending decisions. In some cases, consumerism is a gateway to other individual activities that support the upscaling and sophistication of IBEG. In others, consumers shape the development of IBEG through their role as an imagined collective. By this, we mean that other stakeholders often work to advance IBEG because they anticipate a response from a mass of consumers. Importantly, this anticipated response may be decidedly different from the observed behavior of individual consumers. 
Our overarching conclusion is that consumers matter for IBEG far beyond the purchasing decisions of individuals. We develop a conceptual framework that illustrates how information drives behavior change through a number of direct, indirect, and interconnected pathways. By emphasizing the linkages between different pathways of influence, this framework expands on existing accounts of how information disclosure drives change-which tend to conceptualize information as exerting influence through self-contained channels (Earnhart, Khanna, \& Lyon, 2014; Lyon \& Shimshack, 2015; Powers, Blackman, Lyon, \& Narain, 2011). Our framework implies a modest rethinking of the research agenda on improving the market uptake and sophistication of IBEG toward one that places less primacy on individual consumer recognition of IBEG programs and willingness to pay for green products and more emphasis on consumerism as a gateway to other forms of action and consumers (writ large) as important influences on the decision-making processes of other stakeholders. This conclusion also likely applies to individuals who utilize IBEG programs primarily as investors or employees as well. While beyond the scope of our analysis, the "shadow of the investor," for example, is a natural area for future research, as the effects of investors may also operate through both direct and indirect pathways.

We proceed as follows: the article begins by reviewing some of the existing literature from management, psychology, and economics on how consumers contribute to the upscaling and growing sophistication of IBEG. We then juxtapose the conventional narrative against our novel conceptual framework, which offers a broader account of consumer agency. ${ }^{1}$ We conclude by offering insights into the future growth of IBEG and suggesting avenues for further research.

\section{Voting With Their Wallets: The Prospects and Limits of Individual Consumer Influence}

Before delving into the scholarly work on IBEG, some conceptual ground clearing and explanation of our scope conditions are first necessary. For the purposes of this article, we use Bullock's (2017) definition of IBEG as the use of information to encourage and enable the creation of environmental public or common goods (i.e., nonexcludable goods that are often underproduced by private interests). More specifically, IBEG programs generate publicly available environmental evaluations of products, companies, or other entities, and thus do not include internally oriented environmental management systems, which are generally not public, or corporate sustainability reports, which are generally descriptive and not evaluative (Bullock, 2017). They include certifications such as ENERGY STAR, multi-tier certifications such as LEED, rankings such as UMass Amherst's Toxic 100 Ranking, ratings such as Greenpeace's Greener Electronics Guide, boycotts/watch lists such as Ceres' Climate Watch List, databases such as the Toxics Release Inventory, and reviews such as Green America's Responsible Shopper (Bullock, 2017). These programs all differ from both regulation-based governance strategies that rely on the force of law and market-based governance (e.g., taxes or subsidies) that utilize financial incentives (Bullock, 2017); they only provide information, which people are free to use or disregard.

In terms of the scope of our analysis, we are interested explicitly in IBEG programs that are created by an independent third party and that are consumer facing. We therefore exclude business-to-business environmental standards and proprietary or in-house standards or ecolabels (e.g., Nike Considered Design) from our analysis. The consumer-facing IBEG programs included in our scope may evaluate either products or companies. For example, consumers may look at either the environmental rankings of car manufacturers by the Union of Concerned Scientists or Environmental Working Group's ratings of specific car models, or both, when 
they are considering a new automobile purchase. While the extent to which the information produced by these programs is directly used by consumers varies (e.g., TRI vs. ENERGY STAR), it is all available to consumers and its effectiveness can be enhanced if large numbers of consumers make use of it.

Our analytical focus is thus on the consumer's role in explaining the uptake and increasing sophistication of these IBEG programs. Uptake refers to the degree to which different actors use IBEG programs, or put differently, the number of rule takers adopting an IBEG program (Kalfagianni \& Fuchs, 2015). At least some level of such uptake is necessary for these programs to generate environmental outcomes. One measure of uptake is the growing market share of certified or eco-labeled production vis-à-vis conventional production (Potts et al., 2014), while another might be the number of users who consult a particular environmental ranking. Sophistication refers to the rigor and credibility of the procedures through which IBEG programs establish, enforce, and evaluate their programs. ${ }^{2}$ Such procedures form an integral part of credibility as they define the inputs through which IBEG programs are established, calibrated, and enforced (van der Ven, 2019).

We should caveat that we are not claiming that all varieties of the growing sophistication of IBEG will necessarily lead to stronger environmental impacts, as this would be a tenuous causal leap. Rather, we are simply recognizing that IBEG programs are generally becoming more sophisticated in their attempts to gain the legitimacy and political authority necessary to govern (Bernstein \& Cashore, 2007; Cashore, 2002), and that some level of such sophistication is likely necessary for their effective operation. Market uptake and sophistication are, therefore, two independent variables - but by no means the only ones - that hold a probabilistic relationship to environmental impacts. In other words, those IBEG programs that are broadly used and carefully designed to create behavioral change are more likely to create significant environmental outcomes, all other things being equal (Kalfagianni \& Pattberg, 2013). This relationship between market uptake and sophistication to environmental impacts makes explaining the former an important objective for IBEG scholars and practitioners.

As noted above, an extensive and multidisciplinary literature addresses the role of consumers in promoting the uptake and sophistication of IBEG programs. Work in behavioral economics, for example, emphasizes the role of individual consumers in making an "active choice" to support greener products (Hedlin \& Sunstein, 2016). Work in psychology notes the importance of prior consumer beliefs in determining product choices (Teisl, Rubin, \& Noblet, 2008). Work in business strategy points to the importance of IBEG design in shaping consumer choices (Heinzle \& Wüstenhagen, 2012). A complete analysis of this literature is out of the scope of any one paper. Our goal is somewhat more modest; we seek to highlight some of the broader trends in research linking consumers to the market uptake and sophistication of IBEG. The most notable of these trends is the overwhelming focus on direct consumer engagement through the purchasing of goods. We term this the direct engagement pathway connecting consumers to the market uptake and increasing sophistication of IBEG. In essence, IBEG programs are thought to expand their market share and become more sophisticated when consumers are able to recognize the information they provide, comprehend that information, connect it to their own values, pay for any premiums associated with that information, and maintain a stable commitment to using the information and paying those associated premiums. As we detail below, the many requirements for consumers along this direct engagement pathway are fraught with obstacles and uncertainties. While many IBEG programs have been remarkably successful in overcoming these obstacles, they may equally inhibit the broader usage and effectiveness of this form of governance. 


\section{Awareness}

To start, the direct engagement pathway posits that in order for consumers to exert any kind of influence over IBEG, they must first be able to recognize an IBEG program. However, the multiplicity of ratings and labels in the market makes building consumer awareness and recognition of particular IBEG programs difficult (Leire \& Thidell, 2005). As a 2017 survey shows, more than $50 \%$ of consumers know a little or a lot about only four certifications-Fairtrade, USDA Organic, Certified Kosher, and ENERGY STAR—out of 23 surveyed labels (Hartman Group, 2017). Newer IBEG programs are unlikely to hold the same level of recognition. For example, the Carbon Trust, a British public-private organization, experimented with putting a carbon footprint on products like orange juice and potato chips. However, a 2010 survey of British shoppers found that after 2 years only $20 \%$ of consumers recognized The Carbon Trust's footprint label, versus $82 \%$ for Fairtrade and 54\% for organic labels ("Following the Footprints," 2011). Yet even time is no guarantor of recognition. A 2012 survey of 4408 respondents in the United Kingdom, France, Germany, Spain, Sweden, and Poland found that only $12 \%$ of respondents had seen the EU Eco-Label before, despite the fact that the EU Eco-Label has been used for over 25 years and is present on over 38,000 distinct products in the EU (European Commission, 2017; Grunert, Hieke, \& Wills, 2014). If consumers do not recognize these IBEG programs, then they are less likely to utilize them in their purchasing decisions or advocate for their use more broadly.

\section{Comprehension}

Following the logic above, once an individual observes and recognizes a label, he or she must then comprehend what it stands for before acting on it. Comprehension is particularly important for separating sophisticated IBEG programs from shallower ones. The profusion of labels, rankings, standards, and certifications across commercial sectors in recent years has led to concerns that consumers are confused and bewildered by the deluge of information that confronts them on each trip to the grocery store (Prag, Lyon, \& Russillo, 2016). In farmed seafood alone, there are currently four international third-party eco-labels and a myriad of ranking schemes and domestic labeling initiatives that simultaneously compete for consumer attention. ${ }^{3}$ Given that the average consumer spends 13 seconds making a purchasing decision (Beard, 2015), consumers may not have the time, interest, or ability to take into account the sophistication of competing IBEG programs in their purchasing behaviors. Thus, while consumers may prefer more sophisticated IBEG, they may often not be able to identify and support it.

\section{Value Alignment}

Another issue pertains to the alignment of sophistication with consumer values. As past research has shown, consumers seek different qualities in IBEG programs (Bullock, 2015, 2017). Some might prefer that organizations developing standards, certifications, rankings and labels include technical experts from industry, while others might oppose their inclusion. Some might prefer a strong role for government, while others would find this less desirable. Consumers might favor IBEG programs with a different blend of stakeholders depending on which attributes or issues they find important (e.g., environmental impacts vs. health benefits vs. product quality; Johnston \& Roheim, 2006). Evaluations of sophistication are therefore highly subjective and determined by a range of exogenous variables. They may also evolve over time, as consumers develop new concerns or enter new phases in life, such as having children. The central lesson is that consumers are not a homogenous body that universally 
seeks sophisticated IBEG. Consequently, to the extent that individual consumers use their money to support certain IBEG programs, they may be offering uneven and conflicting signals to the IBEG market.

\section{Willingness to Pay}

Even if one assumes that consumers recognize products governed by IBEG programs and are capable of correctly interpreting the social and environmental values they espouse, they may not be willing to pay a premium for them. An extensive literature addresses consumers' willingness to pay a premium for sustainable goods (Loureiro, McCluskey, \& Mittelhammer, 2002; Sörqvist et al., 2013). A full review of this literature is out of the scope of this article, but two metaanalyses will suffice to summarize some of their findings and highlight some of their associated limitations. From their analysis of the results of over 80 research papers, Tully and Winer (2014) find that $60 \%$ of consumers are willing to pay a premium of for socially responsible products, and that premium is $16.8 \%$ on average. They also conclude that certification increases their willingness to pay by $7 \%$ on average, and that willingness to pay is greater for products that benefit humans as opposed to the environment. Yet, from other research, we know that willingness to pay depends on a range of consumer-specific variables like gender, age, income group, education, and geographic location, as well as product-specific variables like price, brand, quality, and nutritional information (Gutierrez \& Thornton, 2014). Some consumers are unwilling to pay for environmental attributes even when there is no price premium whatsoever (Kitzmueller \& Shimshack, 2012). Hence, at best, the pathway between willingness to pay and improved IBEG uptake and sophistication is a tenuous and highly variable one.

\section{Demand Stability}

Even when consumers are willing to pay premiums for sustainable products, market demand can be short-lived and fickle. For example, when Clorox's popular Green Works line of household cleaners was launched in 2008, it was priced about $20 \%$ higher than conventional cleaners (Levere, 2013). However, by 2012, Clorox reevaluated its market strategy after a precipitous decline in sales, from US\$53 million in 2009 to US\$32 million in 2012, driven by a return to frugality after the 2008 recession. Clorox removed the $20 \%$ price premium on Green Works products and cut advertising on the product line from US\$25 million per year in 2008 to US $\$ 600,000$ per year in 2011 . According to one industry analyst, Green Works "did not appeal to the classic green consumer. So they're deciding to go after conventional consumers at a lower price point" (Levere, 2013). This case illustrates a broader truism: consumer demand for sustainable goods is often unstable and contingent on exogenous factors. As is frequently the case with environmental values in the industrialized world, support for green products is often a mile wide and an inch deep (Horne, 2009). Outside of the relatively narrow segment of value-driven consumer-activists, there is a risk that the public may not provide stable demand for IBEG by voting with their wallets.

In sum, the literature on direct consumer engagement with IBEG programs presents a puzzle. On one hand, there is certainly evidence that individual consumers can influence the form and usage of IBEG programs through their purchasing decisions. On the other hand, there is also evidence of numerous obstacles preventing them from doing so. Consumers may not recognize IBEG, be capable of separating credible from noncredible programs, support increasing sophistication, or be willing to pay for it over the long term. Yet, despite these obstacles, market uptake and sophistication of IBEG programs continue to increase. The answer to this puzzle, we argue, can be found by adopting a broader conception of consumer agency that incorporates multiple pathways of influence and ontologies for consumers. 


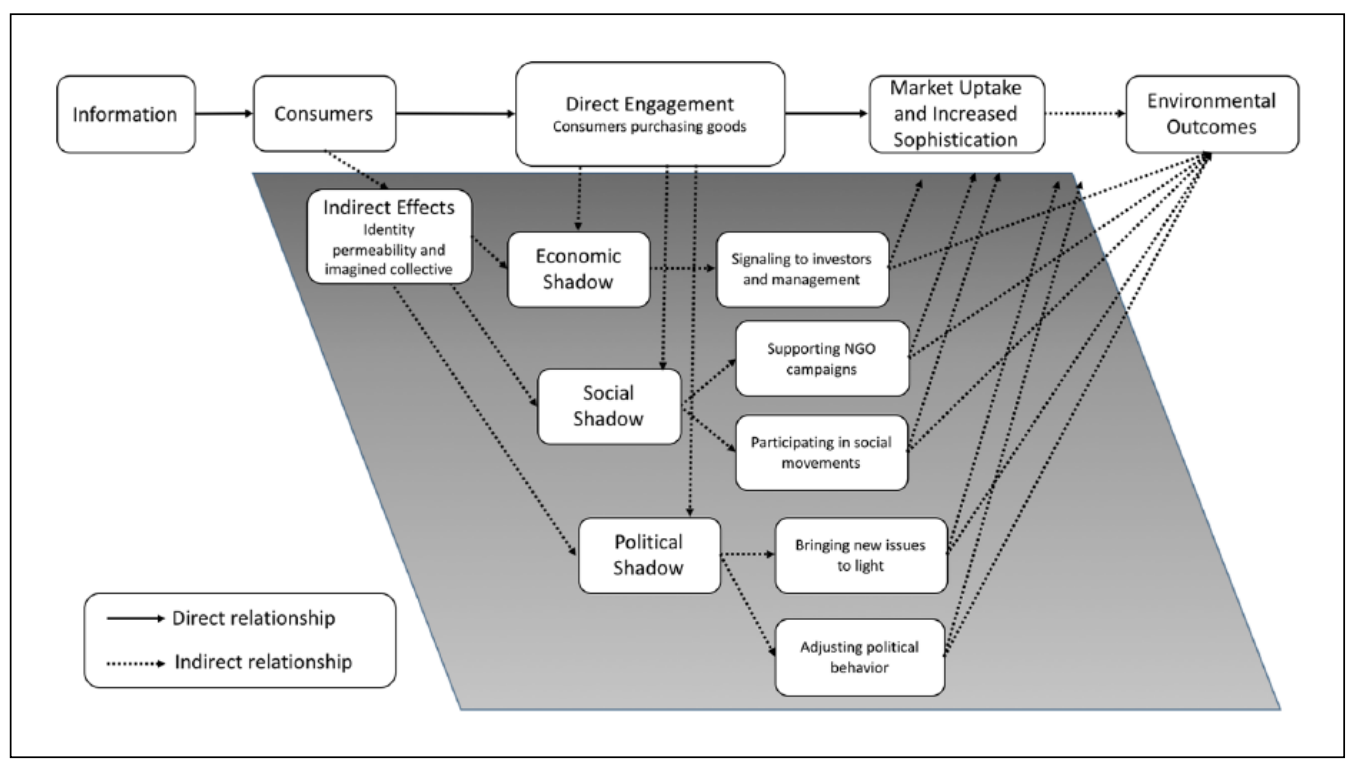

Figure I. The shadow of the consumer.

\section{The Shadow of the Consumer: A Conceptual Framework}

In addition to direct engagement, our novel conceptual framework highlights the many indirect mechanisms through which consumers may influence the uptake and sophistication of IBEG programs. As illustrated in Figure 1, we call these mechanisms the "shadow of the consumer." The shadow of the consumer metaphor is similar to the "shadow of the state" metaphor advanced by Abbott and Snidal (2009), which was developed as a corrective to the proposition that the state was retreating or losing power in the late 20th century. The shadow reflects the important latent power of the state (or, in this case, the consumer), even as other actors appear to be driving economic, political, and social change. In the context of global governance, those actors include private enterprise and civil society organizations. In the context of IBEG, they include elite actors within corporations, nongovernmental organizations (NGOs), government agencies, and rating institutions.

The shadow of the consumer is a novel metaphor for theorizing the relationship between consumers and IBEG programs because it acknowledges the multiple distinct ontologies of consumers. That is, it differentiates between causal effects resulting from the actual observed behavior of individual consumers (i.e., willingness to pay) and the anticipated behavior of groups of consumers. While extant research tends to focus on the former, in many cases, the latter may be more relevant to explaining current trends in IBEG. As Figure 1 illustrates, the anticipated behavior of consumers casts a long shadow over the behavior of other stakeholders. Investors may behave in a certain way because they anticipate a collective consumer reaction. Similarly, corporations respond to NGO naming-and-shaming campaigns a certain way because they anticipate that consumers may also collectively respond along relatively predictable lines. Importantly, anticipated consumer behavior can and should be decoupled from observed consumer behavior. As we note in the preceding section, empirical research finds significant obstacles to individual consumers influencing IBEG programs through their spending power. As an important contribution to theory building on this topic, our framework redirects attention to the latent power of consumers and to alternate pathways of influence. 
A social constructivist account of identity and interest is embedded in the relationships we trace in Figure 1 (Adler, 1997). Specifically, we aim to draw attention to the multiplicity and dynamism of individual identities. Individuals wear many hats, as consumers, as voters, and as activists. These identities are not always distinct from one another, rather identity is permeable and subject to influence from other roles and experiences (Checkel \& Katzenstein, 2009). Moreover, identities are subject to change over time (Wendt, 1994). If one accepts these assumptions, then one might equally observe that an individual's identity as a consumer can inform and shape his or her other identities as a voter, activist, investor, or donor to various NGO causes. The ability of consumer issues to shape identity and behavior in other domains is therefore an important and underanalyzed area of consumer influence over IBEG programs. Essentially, being a consumer can act as a gateway to other pathways of influence over IBEG programs.

The ability of information to trigger behavioral change along multiple interacting pathways differentiates our framework from previous ones. Past accounts largely theorize information as influencing behavior through a series of relatively independent channels. For example, investors may respond to signals sent by environmental rankings (Lyon \& Shimshack, 2015). Alternately, information disclosure may exert pressure on firms through nongovernmental external pressure channels, like critical scrutiny from civil society groups (Earnhart et al., 2014; Powers et al., 2011). Our shadow of the consumer framework builds on these accounts by illustrating the linkages that exist between these different pathways of influence. It acknowledges that the behavior of consumers, investors, and civil society groups are connected and that action through one channel often catalyzes action through other channels.

The first two causal arrows at the top of Figure 1 capture the direct engagement pathway through which consumers influence the market uptake and sophistication of IBEG programs and thereby generate positive environmental outcomes. As noted in the preceding section, individual consumers sometimes vote with their wallets to support certain types of IBEG. Consumer demand can create the conditions for strong market uptake of IBEG. Moreover, consumer differentiation between IBEG programs may create the demand for more sophisticated IBEG. These first-order causal relationships are illustrated by solid arrows, since they arise from actions that consumers might take as they directly engage with and respond to IBEG programs in their identities as consumers.

Indirect relationships, represented by dashed arrows, are those that arise from actions that consumers might take that extend beyond simply voting with their wallets. The cause-andeffect link for these indirect relationships is necessarily more tentative, since it depends on individuals making connections and commitments beyond the immediate context in which they initially encounter the IBEG program. They are therefore best conceived as probabilistic relationships insofar as an informed consumer may be more likely to take action through other channels, but informed consumerism is neither a necessary nor a sufficient condition for taking other forms of action. For example, information about the environmental consequences of a particular product category (e.g., cosmetics) may not only inspire an individual to alter their purchasing behavior but also spur interest in supporting NGO efforts to increase the uptake or sophistication of that information or to lobby for new regulations associated with that product. In other words, an individual's identity as a consumer may occasionally reinforce and activate a complimentary identity as an NGO donor, social movement participant, or concerned observer. Such indirect relationships require that an individual's values extend across his/her different identities and that individuals take action based on those values and in response to information they receive from their environment.

Dashed arrows may also represent a shifting ontology, from how consumers are observed to behave to how they are anticipated to behave. Corporations, politicians, investors, and social movements often have preconceived ideas about how consumers will respond to certain external stimuli. These ideas may differ markedly from how consumers currently behave. For example, a 
corporation may fear a consumer backlash for its environmental practices and preemptively partner with an IBEG program to bolster its reputation. The threat of consumer action is therefore relevant, but the relationship between consumers and IBEG is indirect. Consumers, in these cases, are an imagined collective that influences the behavior of other stakeholders important to IBEG programs through their expected reactions. Note that these anticipated reactions differ from the observed accounts of consumer behavior described earlier, in which consumers rarely act homogenously and are often indifferent to IBEG. For this reason, anticipated consumer behavior is a different and less direct relationship. It is important to note that indirect relationships of this sort outnumber direct ones, thereby suggesting that a narrow focus on consumer purchasing decisions fails to capture many of the ways in which consumers - both as individuals and as an imagined collective-affect the market uptake and sophistication of IBEG and the generation of environmental outcomes more generally.

We can divide the shadow of the consumer into three categories of causal mechanisms. The first is the "economic shadow," which involves senior management or investors anticipating changes in consumer spending and responding proactively by advocating for changes in their corporate strategy, supply chain management, and level of engagement with IBEG. Managers may, for example, implement new or improved corporate environmental management programs that result in additional environmental outcomes and/or the broad adoption of sophisticated IBEG programs. Alternatively, management may anticipate stable long-term demand for a product and begin using a sophisticated IBEG program to sustainably manage that product, thereby leading to market uptake and increasing sophistication. Similarly, investors may anticipate consumer backlash against a particular product and respond by pressuring firms they own to pursue certification or better rankings for that product. Consumers exert influence in this shadow principally through their latent power over senior management and investors.

The second indirect pathway in Figure 1 is the "social shadow." This shadow recognizes the influence of an individual's identity as a consumer on their identities as activists, donors, volunteers, or social media users. While such identities can of course develop independently as well, the assumption here is that concerns that arise in one's capacity as a consumer occasionally translate into other forms of social action. For example, someone who learns about animal welfare issues through the purchase of foie gras or a goose-down jacket may be more likely to support animal welfare causes more generally. Such support and participation might include donating to NGOs, volunteering, posting on social media, or protesting in the streets. These actions can simultaneously create pressure on government agencies to adopt new policies, firms to utilize IBEG programs, and IBEG programs to become more sophisticated.

Last, at the bottom of the diagram, is the "political shadow" of the consumer. Closely related to the social shadow, this shadow includes political actions taken by individuals that are inspired or catalyzed by their identity as consumers. For example, buying an ENERGY STAR certified appliance might lead an individual to support a political party or candidate that advocates for greater subsidies for energy efficient home appliances. Alternately, concern over the environmental impact of particular product categories (e.g., chemical cleaners) may lead individuals to vote for politicians who are committed to stronger environmental laws. These actions, in turn, may create conditions favorable not only for the passage of new environmental laws but also for the uptake and increasing sophistication of IBEG programs. Here again, the relationship is indirect and involves an individual's identity as a consumer informing and shaping his or her identity as a political actor.

The shadow of the consumer can help explain why the market uptake and sophistication of IBEG programs has continued to grow notwithstanding the considerable barriers to direct consumer engagement through purchasing power. As Figure 1 shows, consumers cast a long shadow both in how their anticipated behavior affects others and in how consumer identity permeates other parts of self-identity. We acknowledge the fact that the shadow of the 
consumer looms larger over some areas than others. The relationship between anticipated consumer behavior and investor decisions, for example, is much more straightforward than the relationship between consumer behavior and voting decisions. For this reason, the shadow is darker at the top of the diagram than at the bottom. While not shown in the diagram and beyond the scope of this article, the different shadows of the consumer may themselves interact and influence each other in important ways - for example, signals to investors may have an effect on social movements or political behavior. Also, the direction of causality may be reversed in some cases - for example, an individual's political actions may influence their consumer behavior. Below, we explore the different shadows in greater detail using insights and examples from the literature to illustrate causal mechanisms and obstacles associated with each of them.

\section{The Economic Shadow}

The economic shadow of consumers falls particularly long across decisions made by senior managers and investors to use IBEG or partner with sophisticated IBEG programs. Specifically, the desire to win new consumers or the fear of losing existing consumers can form a strong impetus for business uptake of IBEG. One might start with the observation that decisions to use IBEG are often made by senior managers within firms (Thauer, 2014). A growing number of retailers are entering into exclusive sustainable sourcing commitments in partnership with third-party IBEG programs. For example, Costco has partnered with the Marine Stewardship Council (MSC) and ASC as part of its commitment to source sustainable seafood (Costco, 2017). In this case, individual consumer decisions to purchase or not purchase certified seafood appear irrelevant since senior management has committed to offering only certified sustainable options. Nonetheless, the latent power of consumers is often evident in managerial decisions to partner with IBEG programs. While a range of variables may have influenced Costco's decision to partner with MSC and ASC (McWilliams, Siegel, \& Wright, 2006; van der Ven, 2014), it is highly unlikely that management would have made this decision without first considering how it would help the retailer attract and retain consumers.

As an example of this dynamic, when Walmart was overhauling its sustainability policies in 2006, it created a new Live Better Index to serve as an "ongoing barometer of consumer attitudes shopping behaviors." Its benchmark findings show that $57 \%$ of Americans are extremely concerned about the environment, $62 \%$ would buy more eco-friendly products if there was no price difference, and $78 \%$ stated they "need more information to think about how to help solve environmental issues" (Walmart, 2007). These results were both implicitly and explicitly used to justify Walmart's efforts to sell more environmentally friendly products, from CFL lightbulbs to organic baby food.

The anticipated reaction of consumers was therefore central to decisions by senior management at Walmart to partner with IBEG programs. Yet, even when the economic shadow of the consumer is less immediately evident, one must still account for the influence of anticipated consumer behavior. For example, McDonalds' decision to obtain MSC certification for the Alaskan Pollock used in its Filet-O-Fish sandwiches initially appeared to be driven by concern about the long-term resilience of the Pollock fishery (Greenpeace, 2014). As Bob Langert, the vice president of sustainability for McDonald's, commented in 2013: "We've had sustainable fish for many years, but we didn't tell people about it" (Gunther, 2013). Here again, the impact of consumer purchasing decisions appears to be marginal since consumers can only vote with their wallets when an IBEG program is visible. However, Langert goes on to say that "we see the consumer starting to care" and that the move to adopt MSC certification is eventually "going to contribute to an increase in our sales" (Gunther, 2013). Langert's stated rationale suggests a product differentiation strategy that would allow McDonalds to gain an advantage 
over its competitors (Crifo \& Forget, 2015). Hence, even if corporate decision makers are ambivalent about today's consumers, they still often factor tomorrow's consumers into their decisions to use IBEG.

While the economic shadow of the consumer often provides "carrots" for IBEG uptake, it can equally function as a more coercive "stick." If management or shareholders anticipate that consumers will abandon their product or service due to environmental transgressions, they may be strongly motivated to partner with IBEG programs. Additionally, they may push for more sophisticated IBEG programs that are capable of withstanding critical scrutiny. To unpack this dynamic, one must first consider the relationship between consumers and investors. Investors often anticipate consumer reactions by alternately investing or divesting their capital from particular firms. If something happens that might drive consumers away, investors often react proactively by shifting their funds elsewhere. Perhaps for this reason, past research has established a discernible negative effect of NGO naming-and-shaming campaigns on share prices (Bartley \& Child, 2011). When naming-and-shaming threatens to drive consumers elsewhere, shareholders react by moving their investments to safety, and thus, share prices fall. Senior executives in large firms have a fiduciary duty to protect their investors from reputational risks affecting share price, thus, they often use IBEG programs because of their insurance-like properties (Godfrey, Merrill, \& Hansen, 2009). An endorsement from a sophisticated, third-party IBEG program is an excellent means of protecting a firm's reputation. Importantly though, a firm's reputation is significant primarily for its ability to attract and retain consumers.

As global value chains elongate and become more complex, businesses are increasingly exposed to reputational risk through the actions of their suppliers. Uptake of IBEG offers a form of 'brand insurance' that can guard against reputational risks from the actions of value chain partners (Werther \& Chandler, 2005). Certifications and labels are particularly useful in this regard. The chief sources of these risks are negative media coverage, NGO naming-and-shaming campaigns, poor ratings and boycotts. The empirical effects of this type of pressure on large "lead firms" in global value chains are by now well-documented (Gereffi, 2014; Lyon \& Maxwell, 2004). The pressure is particularly acute for highly visible brands (e.g., Nike or Disney) that are vulnerable to attacks from both activist NGOs, and increasingly, social media users (Dauvergne \& Lister, 2013).

Admittedly, reputational risk may not be a sufficient condition for uptake of IBEG. Firms may respond to such risk with a range of other actions, including "going it alone" and devising their own systems of value chain governance. The risk of going it alone is that corporate actions may be misleading, poorly conceived, or sloppily executed, thereby leading to durable reputational damage (Chen \& Chang, 2013). Engaging a sophisticated third-party IBEG program, by contrast, adds a layer of impartiality and legitimacy to corporate social responsibility and helps minimize the risk of NGO naming-and-shaming. The reputational risk of being accused of "greenwashing" creates an incentive for brand-sensitive firms to partner with sophisticated IBEG programs, particularly those that are developed through inclusive multistakeholder processes and can demonstrate impartiality (van der Ven, 2019). The advent of social media has further heightened the pressure for lead firms to ensure that their mechanisms for supply chain governance are sufficiently robust. Instances of poorly thought-out corporate social responsibility are liable to get "tweetjacked," as they are repurposed by Internet users to illustrate corporate hypocrisy (Lyon \& Montgomery, 2013). Hence, the drive for sophistication and stringency in IBEG ironically often comes from the business users of such schemes (van der Ven, 2019).

Importantly, the reputational risk discussed above is largely contingent on the anticipated behavior of consumers. While companies may be concerned about investor reactions to NGO naming-and-shaming campaigns, these reactions may in turn be primarily based on concerns about how consumers will respond to naming-and-shaming campaigns. Given that only $22 \%$ 
of investments are held in so-called socially responsible investment options (The Forum for Sustainable and Responsible Investment, 2016), changes in share prices due to activist campaigns are most likely driven by risk-averse investors who are not concerned with the ethical performance of companies per se, but with the effect of sustainability performance on companies' revenues, market share, and profitability. If there were no risk that consumers would shift their business away from companies identified as bad actors, these investors would likely not be concerned with how activists perceive and frame those companies.

The same is true for the downstream retailers and aforementioned brands like Walmart or Costco. While their power over global value chains is indeed vast, they likely would not care as much about the sustainability of those value chains if they did not envision some significant percentage of consumers contributing to a backlash against them. For example, Walmart might not have initiated its sustainability transformation in 2006 absent the threat of consumers punishing it for poor sustainability performance. Indeed, the anticipated reaction of consumers to controversies surrounding water in India and South America for Coca Cola (Brodzinsky, 2003; Hoffman, 2006; Mathiason, 2006) and low wages and treatment of workers for Walmart (Massengill, 2013; Norman, 2004; Plambeck \& Denend, 2008) are among the primary drivers of their deep engagement with sustainability issues. It is equally doubtful that these companies would fear "tweetjacking" if consumers ultimately did not care about the issues being tweeted about. Thus, consumers cast a long economic shadow. While the influence of consumers may often be indirect, it is by no means tangential or unimportant.

\section{The Social Shadow}

The social shadow of the consumer involves individual consumers responding to IBEG programs by supporting NGOs or getting involved in social movements that either work toward improving environmental outcomes generally or increasing the market uptake or sophistication of IBEG programs specifically. As evinced in the preceding section, social pressure or NGO naming-andshaming campaigns can help drive both trends in IBEG. Both of these forces are indirectly linked to consumers through the social shadow. For example, consumer concern over particular products or companies may drive them to donate to a particular NGO, participate in a social movement, or leverage the power of social media to call for better IBEG. As noted earlier, individuals often embody multiple permeable identities. Decisions made in one's role as a consumer can influence decisions made in other aspects of one's social life. A decision to purchase Rainforest Alliance certified coffee may increase an individual's support for conservation causes, and vice versa. Alternatively, a consumer encountering an example of fraudulent or false environmental marketing might cause them to tweet about it.

Scholars term the link between conscious consumerism and activism "crowding-in" (Willis \& Schor, 2012). While still limited, there are well-documented studies of its occurrence. In a 2008 survey of over 2,200 American consumers, for example, researchers found that nearly one out of five respondents became more politically and socially active after they began practicing conscious consumption (Willis \& Schor, 2012). Clearly then, not all concerned consumers will become social activists, and not all social activism is caused by consumer experiences. Thus, the social shadow of the consumer has its limits. However, when considering the broader influence of consumers over IBEG, it is important to recognize that consumerism can serve as a gateway to other actions that have important effects on IBEG programs, as Willis and Schor's (2012) work demonstrates. This is an understudied area of consumer influence and one that is brought to light through the shadow of the consumer framework.

Understanding the influence of the social shadow involves first understanding the mechanisms that hold both firms and IBEG programs accountable (van der Ven, in press). Unlike democratically elected governments, firms and IBEG programs do not face routine elections. 
Rather, the ability to hold firms accountable is dispersed among their stakeholders: employees, investors, consumers, NGOs, and the media, among others. NGOs and rating organizations in particular play an important role as "watchdogs" of both firms and IBEG programs, using their moral legitimacy to advocate for the common good (Baur \& Palazzo, 2011). In this sense, NGOs and rating organizations serve as proxies for concerned consumers and members of the public and help aggregate broader interests to exert pressure on both firms and IBEG programs.

Following the economic logic of comparative advantage, consumers often choose to outsource their concerns over particular firms or IBEG programs to NGOs or rating organizations, since they often have more time, expertise, and resources to effectively influence firms and IBEG programs. In doing so, they may appear to be abrogating their role as consumers, but decisions to donate to a particular NGO or subscribe to a particular rating publication are often made precisely because of an individual's identity as a consumer. For example, consumers may support a third-party organization - either through donations or by buying their products - as they seek advice on product decisions. Consider the awards and ratings provided by Consumer Reports, JD Power, and a range of mainstream and niche media outlets. Such delegation is not an abrogation of consumer identities, but merely their extension into a different realm. After all, one's identity as a consumer is likely what would lead one to purchase a membership in Consumer Reports, for example. This, in turn, provides a third-party actor with the means to hold firms and IBEG programs accountable for their environmental impacts, thereby creating pressure for both market uptake and sophistication in IBEG programs.

Existing evidence suggests that the pressure exerted by activists and social movements - both of which are often supported by consumers - is a critical driver of the uptake and sophistication of IBEG more than consumer purchasing decisions. For example, Baron (2011) finds that social pressure is what drives demand for stringent sustainability standards. His conclusion is premised on the idea that higher standards, informed by sophisticated inputs, tend to increase the price of a product/service. Put simply, products that comply with a stringent sustainability standard generally cost more to produce because the firms that make them undertake costly behavioral changes in order to achieve compliance. The resulting price increase reduces consumer demand for the certified or eco-labelled good. With potentially weakened consumer demand for those products, NGO campaigns and other forms of social pressure that affect brand reputation emerge as vital mechanisms of support for sophisticated IBEG. While Baron's (2011) model also assumes and requires that at least some consumers have a preference for the certification and that they will pay a premium for the product if they are confident in the certification's validity, it shows the complementarity and positive reinforcement between consumer demand and the actions of activist organizations. The relevance of consumers thus appears to lie as much in their indirect role of supporting NGOs, rating agencies, and social movements as in their direct role in purchasing certain types of products.

\section{The Political Shadow}

The final indirect pathway through which consumers exert influence over IBEG programs is through the "political shadow." This shadow is arguably the least understood and least studied, and yet has considerable potential to shape the direction of IBEG. Much like the social shadow, the idea is that an individual's identity as a consumer can ripple outward into other identities, such as that of a voter and citizen. This pathway involves individuals who have been exposed to information from IBEG efforts changing their political behavior (e.g., by voting for candidates voicing environmental concerns), which can then lead to new policies that increase the market uptake and sophistication of IBEG programs or generate environmental outcomes directly. 
The most easily observable example of the former mechanism comes from the history of organic food. Concern among consumers about fraudulent organic food and conventional foods being treated with pesticides and other chemicals (e.g., Alar) during the 1970s and 1980s were key drivers of the effort to create a standardized label for organic products (Obach, 2015). Consumer organizations such as Americans for Safe Food Project and Public Voice for Food and Health Policy were part of an "increasingly mobilized consumer base that fueled the push" toward a national organic standard, which was ultimately called for by Congress in the Organic Foods Production Act of 1990 (Obach, 2015, pp. 71). Thus, consumer concerns about the lack of consistency and clarity in state and private organic standards contributed to the creation of the USDA Organic label, which has enabled far greater market uptake of certified organic food and is arguably more sophisticated than its predecessors. Examples of this trend may be equally observed across other sectors and issue -areas. For example, the EU's 2013 ban on animal testing, which was at least in part driven by consumer concerns, likely created conditions favorable to cruelty-free certifications, particularly for foreign producers seeking access to lucrative European markets (“EU Bans Animal,” 2013).

Given the fact that consumer issues often become political issues, it is not difficult to imagine that an individual's stance on environmental policy might be influenced by an issue that they first confront in the grocery store. The difficulty here is in determining the direction of the causal arrow. Do consumers buy green products because of their existing values or are values shaped by consumer behavior? Past research has found that hybrid vehicles and LEED certified buildings tend to cluster in regions with observably strong environmental values; however, it is difficult to determine prima facie whether driving a Prius makes someone more of an environmentalist or is a result of their existing environmentalism (Kahn \& Vaughn, 2009). While the relationship is indirect, the idea that green consumerism leads to green political behavior warrants careful consideration. As previous research has shown, green consumerism is often an entry point for more radical steps toward sustainability (Thøgersen \& Noblet, 2012).

\section{Conclusion}

Certifications, voluntary standards, eco-labels, and sustainability rankings have increasingly moved from the periphery to the center of global markets. IBEG programs, as we call them, are expanding their market uptake in nearly every commercial sector and region. Furthermore, the procedures through which IBEG programs are established, calibrated, and enforced are growing more sophisticated. Guidelines of best practice, codes of conduct, and experiential learning have combined to make IBEG programs more transparent, inclusive, and impartial than ever before. Yet existing research suggests lingering barriers to consumer engagement with IBEG programs. Individual consumers struggle to recognize IBEG programs, have difficulty separating credible from noncredible programs, and are only occasionally willing to pay more for products that use IBEG. All of which suggests that consumers have, at best, mixed opportunities to support IBEG through their purchasing decisions. This presents a puzzle: is it possible consumers are playing a larger role that has gone mostly undetected in the extant literature?

To address this question, we have advanced the metaphor of the shadow of the consumer. We have argued that consumers are contributing to the uptake and increasing sophistication of IBEG through a number of indirect channels or "shadows." In the economic shadow, other stakeholders make decisions that influence IBEG uptake and sophistication out of concern for the anticipated reaction of consumers. Specifically, senior managers and investors may push large firms to demand sophisticated IBEG out of a concern for how consumers - as an imagined collective - may react. They often see IBEG as a means of gaining and retaining green consumers or as a means of protecting against reputational damage and 
the accompanying loss of consumer business. In either case, the economic shadow of the consumer weighs heavily on their decisions and holds repercussions for the state of IBEG. Thus, while individual consumer choices may play a marginal role in shaping the future of IBEG, the looming threat of an imagined collective of consumers is an influential factor in elite decision making.

In the social and political shadows, identities and interests formed through consumerism occasionally lead individuals to pursue other forms of action with consequences for IBEG. These actions may include donating to NGOs that help hold firms and IBEG programs accountable or supporting legislation that advances environmental goals or creates enabling conditions for market uptake of IBEG. In either case, social and political actions are often catalyzed by an individual's experiences as a consumer (although again, not exclusively so). Hence, while certainly not an exclusive source of influence, as other stakeholders can and have acted independently of consumer pressures (or for complementary reasons), consumers cast a long shadow by virtue of how their identities as consumers inform their identities and interests in other aspects of life.

Thus, our answer to the question of whether consumers "matter" for the uptake, sophistication, and ultimate effectiveness of IBEG is a qualified "yes," though not for the reasons that they are most often assumed to matter. Our analysis points to an imbalance in the literature on IBEG programs in political science, behavioral economics, sociology, law, social psychology, and business strategy. It would seem that a disproportionate amount of scholarship, across these and other disciplines, is devoted to analyzing when individual consumers will or will not buy "green" products (as identified by IBEG programs). This literature rests on the assumption that individual consumer decisions are relevant to the future development of IBEG and, ultimately, the attainment of environmental goals. Our goal has been to explore this assumption and arrive at a more nuanced conception of consumer relevance by charting the broader mechanisms and pathways through which consumers influence IBEG programs. Doing so implies that there is considerable room to broaden the research agenda on IBEG to include a more systematic analysis of how consumers affect IBEG beyond their ability to vote-with-their-wallets.

To be clear, we are not the first scholars to suggest that factors other than individual consumer decisions are driving the growth and sophistication of IBEG (Bartley \& Child, 2014; Poulsen, Ponte, \& Lister, 2016). However, we do make a contribution by systematically tracing the relevance of consumers to other forms of influence over IBEG. In doing so, we readily acknowledge that there are significant limits to the power of the consumers. The latent power of consumers over management and investors is constrained by sector and product-specific factors. Moreover, not all consumers will make the leap to becoming NGO donors, social movement participants, or value-driven voters. Consumer attention to a particular product or issue area may be short-lived and largely ignored (Ettenson, Smith, Klein, \& John, 2006). Even when consumers do mobilize and pursue social or political action, firms may choose to "ride out the storm" in lieu of adopting or pursuing more sophisticated IBEG. Thus, the ultimate influence of the shadow of the consumers on IBEG is constrained by market factors, limited interest levels, short attention spans, and corporate indifference.

These caveats notwithstanding, the framework of the shadow of the consumer provides a useful jumping-off point for a number of areas for future research. For one, the shadow metaphor may be a useful heuristic for explaining why IBEG has flourished in some sectors more than others. If one considers the commercial sectors and regions in which consumers do not cast a long shadow, one might find interesting correlations with a lack of uptake and sophistication in IBEG. As past research has found, sectors that are characterized by a highly engaged consumer base (e.g., kosher foods) have stronger incentives to employ sophisticated IBEG programs widely (Starobin \& Weinthal, 2010). The logical corollary is that those industries that operate outside of 
the likely scrutiny of the consumer may lag behind in both market uptake and sophistication. This is a topic ripe for systematic cross-sectoral comparison.

We also see an opportunity to continue and expand the important work that has been done on negative and positive spillover effects from consumer-oriented initiatives (Steinhorst, Klöckner, \& Matthies, 2015; Truelove, Carrico, Weber, Raimi, \& Vandenbergh, 2014; Zhou, $\mathrm{Liu}, \mathrm{Mao}, \& \mathrm{Yu}, 2017)$. These initiatives may either encourage consumers to engage environmental issues as both consumers and citizens (a positive spillover or moral consistency effect), or they may discourage further engagement beyond the initial action (a negative spillover or moral licensing effect; Conway \& Peetz, 2012; Evans et al., 2013; Mullen \& Monin, 2016; Tiefenbeck, Staake, Roth, \& Sachs, 2013). We therefore need to better understand the conditions under which IBEG programs crowd-in versus crowd-out other forms of individual action, such as volunteering, donating, protesting, and engaging with elected representatives and other citizens (Berglund \& Matti, 2006; Feldman \& Perez, 2012; Menges, Schroeder, \& Traub, 2005; Willis \& Schor, 2012).

Last, and relatedly, further research is necessary on the political shadow of the consumer. We have provided some empirical examples of consumer identity inspiring political action, yet rigorous scholarly research in this field is in short supply. In particular, we see an opportunity to further explore the relationship between consumer identity and political behavior. Conventional wisdom suggests and empirical research has demonstrated that an individual's values often define his/her purchasing decisions (Newman \& Bartels, 2011). Yet the inverse relationship is equally possible. Decisions to buy certain products may inspire a change in values, particularly when it comes to voting (Thøgersen \& Noblet, 2012). For example, buying an electric vehicle could make an individual more supportive of carbon taxes, tailpipe emissions standards, or the expansion of renewable energy. The political shadow of the consumer is the least developed part of our framework, and therefore warrants particular attention by scholars in the future.

\section{Declaration of Conflicting Interests}

The author(s) declared no potential conflicts of interest with respect to the research, authorship, and/or publication of this article.

\section{Funding}

The author(s) received no financial support for the research, authorship, and/or publication of this article.

\section{Notes}

1. We use the term conceptual framework to mean an "integrated way" of "bringing together a number of related concepts to ... give a broader understanding of the phenomenon of interest - or, simply, of a research problem" (Imenda, 2014). We distinguish this from a deductive theoretical framework or formal model that reflects the application of a well-established theory and makes "specific predictive claims" about the relationships between precisely defined variables (Imenda, 2014).

2. Elsewhere this has been termed a "techno-political approach to the institutionalization of sustainability" (Loconto \& Fouilleux, 2014).

3. These include the following: Aquaculture Stewardship Council (ASC), Best Aquaculture Practices, Friend of the Sea, and Naturland. These certification schemes are supplemented with ranking systems like the Monterrey Bay Aquarium's Seafood Watch program and the comparable Canadian SeaChoice program. The IBEG universe is further complicated by the presence of domestic production standards like VietGAP (Vietnam) and OceanWise (Canada).

\section{ORCID iD}

Hamish van der Ven (iD https://orcid.org/0000-0002-9223-9080 


\section{References}

Abbott, K. W., \& Snidal, D. (2009). The governance triangle: Regulatory standards institutions and the shadow of the state. In W. Mattli \& N. Woods (Eds.), The politics of global regulation (pp. 44-88). Princeton, NJ: Princeton University Press.

Adler, E. (1997). Seizing the middle ground: Constructivism in world politics. European Journal of International Relations, 3, 319-363.

Akenji, L. (2014). Consumer scapegoatism and limits to green consumerism. Journal of Cleaner Production, 63, 13-23.

Baron, D. P. (2011). Credence attributes, voluntary organizations, and social pressure. Journal of Public Economics, 95, 1331-1338.

Bartley, T., \& Child, C. (2011). Movements, markets and fields: The effects of anti-sweatshop campaigns on U.S. firms, 1993-2000. Social Forces, 90, 425-451.

Bartley, T., \& Child, C. (2014). Shaming the corporation: The social production of targets and the antisweatshop movement. American Sociological Review, 79, 653-679.

Baur, D., \& Palazzo, G. (2011). The moral legitimacy of NGOs as partners of corporations. Business Ethics Quarterly, 21, 579-604.

Beard, R. (2015, January 13). Make the most of your brand's 20 second window. Nielsen. Retrieved from http://www.nielsen.com/us/en/insights/news/2015/make-the-most-of-your-brands-20-second-wi ndown.html

Ben, Y. A., \& Abderrazak, C. (2009). Multiplicity of eco-labels, Competition, and the environment. Journal of Agricultural \& Food Industrial Organization, 7(2), 1-24.

Berglund, C., \& Matti, S. (2006). Citizen and consumer: The dual role of individuals in environmental policy. Environmental Politics, 15, 550-571.

Bernstein, S. (2014). The publicness of private global environmental and social governance. In J. Best \& A. Gheciu (Eds.), The return of the public in global governance (pp. 120-148). Cambridge, England: Cambridge University Press.

Bernstein, S., \& Cashore, B. (2007). Can non-state global governance be legitimate? An analytical framework. Regulation \& Governance, 1, 347-371.

Bernstein, S., \& van der Ven, H. (2017). Best practices in global governance. Review of International Studies, 43, 534-556.

Brécard, D. (2017). Consumer misperception of eco-labels, green market structure and welfare. Journal of Regulatory Economics, 51, 340-364.

Brodzinsky, S. (2003, July 24). Coca-Cola boycott launched after killings at Colombian plants. The Guardian. Retrieved from https://www.theguardian.com/media/2003/jul/24/marketingandpr.colombia

Bullock, G. (2015). Signaling the credibility of private actors as public agents: Transparency, independence, and expertise in environmental evaluations of products and companies. Business and Politics, $17,177-219$.

Bullock, G. (2016). Information-based governance theory. In Handbook on theories of governance (pp. 281-292). Cheltenham, England: Edward Elgar.

Bullock, G. (2017). Green grades: Can information save the earth? Cambridge: MIT Press.

Cashore, B. (2002). Legitimacy and the privatization of environmental governance: How non-state marketdriven (NSMD) governance systems gain rule making authority. Governance, 15, 503-529.

Checkel, J. T., \& Katzenstein, P. J. (Eds.). (2009). European identity. Cambridge, England: Cambridge University Press.

Chen, Y.-S., \& Chang, C.-H. (2013). Greenwash and green trust: The mediation effects of green consumer confusion and green perceived risk. Journal of Business Ethics, 114, 489-500.

Conroy, M. E. (2007). Branded! How the certification revolution is transforming global corporations. Gabriola Island, British Columbia, Canada: New Society.

Conway, P., \& Peetz, J. (2012). When does feeling moral actually make you a better person? Conceptual abstraction moderates whether past moral deeds motivate consistency or compensatory behavior. Personality and Social Psychology Bulletin, 38, 907-919.

Costco. (2017). Sustainable fisheries. Retrieved from https://www.costco.com/sustainability-fisheries.html

Crifo, P., \& Forget, V. D. (2015). The economics of corporate social responsibility: A firm-level perspective survey. Journal of Economic Surveys, 29, 112-130. 
Dauvergne, P., \& Lister, J. (2013). Eco-business: A big-brand takeover of sustainability. Cambridge: MIT Press.

Derkx, B., \& Glasbergen, P. (2014). Elaborating global private meta-governance: An inventory in the realm of voluntary sustainability standards. Global Environmental Change, 27, 41-50.

Earnhart, D. H., Khanna, M., \& Lyon, T. P. (2014). Corporate environmental strategies in emerging economies. Review of Environmental Economics and Policy, 8, 164-185.

ENERGY STAR. (n.d.). Facts and stats. Retrieved from https://www.energystar.gov/buildings/about-us /facts-and-stats

Ettenson, R., Smith, N. C., Klein, J., \& John, A. (2006). Rethinking consumer boycotts. MIT Sloan Management Review, 47(4), 6-7.

EU bans animal-tested cosmetics. (2013, March 11). BBC News. Retrieved from http://www.bbc.com /news/world-europe-21740745

European Commission. (2017, June 9). Facts and figures. Retrieved from http://ec.europa.eu/environment /ecolabel/facts-and-figures.html

Evans, L., Maio, G. R., Corner, A., Hodgetts, C. J., Ahmed, S., \& Hahn, U. (2013). Self-interest and proenvironmental behaviour. Nature Climate Change, 3, 122-125.

Feldman, Y., \& Perez, O. (2012). Motivating environmental action in a pluralistic regulatory environment: An experimental study of framing, crowding out, and institutional effects in the context of recycling policies. Law \& Society Review, 46, 405-442.

Following the footprints. (2011, June 2). The Economist. Retrieved from http://www.economist.com /node/ 18750670

Fouilleux, E., \& Loconto, A. (2017). Voluntary standards, certification, and accreditation in the global organic agriculture field: A tripartite model of techno-politics. Agriculture and Human Values, 34, $1-14$.

Fransen, L. (2011). Corporate social responsibility and global labor standards: Firms and activists in the making of private regulation. New York, NY: Routledge.

Gereffi, G. (2014). Global value chains in a post-Washington Consensus world. Review of International Political Economy, 21, 9-37.

Godfrey, P. C., Merrill, C. B., \& Hansen, J. M. (2009). The relationship between corporate social responsibility and shareholder value: An empirical test of the risk management hypothesis. Strategic Management Journal, 30, 425-445.

Greenpeace. (2014). Where do McDonalds Filet-O-Fish sandwiches come from? Retrieved from http: //www.greenpeace.org/usa/mcdonalds-murkowski/

Grunert, K. G., Hieke, S., \& Wills, J. (2014). Sustainability labels on food products: Consumer motivation, understanding and use. Food Policy, 44, 177-189.

Gunther, M. (2013, September 24). Coffee and the consumer: Can McDonald's mainstream sustainability? The Guardian. Retrieved from https://www.theguardian.com/sustainable-business/mcdonalds-coffee -sustainability

Gutierrez, A., \& Thornton, T. F. (2014). Can consumers understand sustainability through seafood ecolabels? A U.S. and UK case study. Sustainability, 6, 8195-8217.

Hainmueller, J., Hiscox, M. J., \& Sequeira, S. (2014). Consumer demand for fair trade: Evidence from a multistore field experiment. Review of Economics and Statistics, 97, 242-256.

Harbaugh, R., Maxwell, J. W., \& Roussillon, B. (2011). Label confusion: The Groucho effect of uncertain standards. Management Science, 57, 1512-1527.

Hartman Group. (2017). Sustainability 2017 report overview and highlights. Retrieved from http:// store.hartman-group.com/content/Sustainability-2017-Overview.pdf

Hedlin, S., \& Sunstein, C. R. (2016). Does active choosing promote green energy use? Experimental evidence. Ecology Law Quarterly, 43, 107-142.

Heinzle, S. L., \& Wüstenhagen, R. (2012). Dynamic adjustment of eco-labeling schemes and consumer choice: The revision of the EU energy label as a missed opportunity? Business Strategy and the Environment, 21, 60-70.

Heyes, A., \& Martin, S. (2016). Social labeling by competing NGOs: A model with multiple issues and entry. Management Science, 63, 1800-1813. 
Hidrue, M. K., Parsons, G. R., Kempton, W., \& Gardner, M. P. (2011). Willingness to pay for electric vehicles and their attributes. Resource and Energy Economics, 33, 686-705.

Hoffman, A. (2006, September 5). Coca-Cola learns a tough lesson about corporate sustainability. Grist. Retrieved from http://grist.org/article/hoffman1/

Horne, R. E. (2009). Limits to labels: The role of eco-labels in the assessment of product sustainability and routes to sustainable consumption. International Journal of Consumer Studies, 33, 175-182.

Imenda, S. (2014). Is there a conceptual difference between theoretical and conceptual frameworks? Journal of Social Sciences, 38, 185-195. Retrieved from https://pdfs.semanticscholar.org/4b40/2748598965cf7 618a6a7ba7f416782f27ca2.pdf

Johnston, R. J., \& Roheim, C. A. (2006). A battle of taste and environmental convictions for ecolabeled seafood: A contingent ranking experiment. Journal of Agricultural and Resource Economics, 31, 283-300.

Kahn, M. E., \& Vaughn, R. K. (2009). Green market geography: The spatial clustering of hybrid vehicles and LEED registered buildings. B.E. Journal of Economic Analysis \& Policy, 9(2), 1-22.

Kalfagianni, A., \& Fuchs, D. (2015). Private agri-food governance and the challenges for sustainability. In Handbook on the globalisation of agriculture (pp. 274-290). Northampton, MA: Edward Elgar.

Kalfagianni, A., \& Pattberg, P. (2013). Fishing in muddy waters: Exploring the conditions for effective governance of fisheries and aquaculture. Marine Policy, 38, 124-132.

Kitzmueller, M., \& Shimshack, J. (2012). Economic perspectives on corporate social responsibility. Journal of Economic Literature, 50, 51-84.

Leire, C., \& Thidell, Å. (2005). Product-related environmental information to guide consumer purchases: A review and analysis of research on perceptions, understanding and use among Nordic consumers. Journal of Cleaner Production, 13, 1061-1070.

Lernoud, J., Potts, J., Sampson, G., Garibay, S., Lynch, M., Voora, V., . . Wozniak, J. (2017). The state of sustainable markets: Statistics and emerging trends 2017. Geneva, Switzerland: ITC.

Levere, J. L. (2013, April 21). Green Works aims to get out of the niche. The New York Times. Retrieved from https://www.nytimes.com/2013/04/22/business/media/cloroxs-green-works-aims-to-get-out-of -the-niche.html

Loconto, A., \& Fouilleux, E. (2014). Politics of private regulation: ISEAL and the shaping of transnational sustainability governance. Regulation \& Governance, $8,166-185$. Retrieved from https://onlinelibrary .wiley.com/doi/full/10.1111/rego.12028

Loureiro, M. L., McCluskey, J. J., \& Mittelhammer, R. C. (2002). Will consumers pay a premium for ecolabeled apples? Journal of Consumer Affairs, 36, 203-219.

Lyon, T. P., \& Maxwell, J. W. (2004). Corporate environmentalism and public policy. Cambridge, England: Cambridge University Press.

Lyon, T. P., \& Montgomery, A. W. (2013). Tweetjacked: The impact of social media on corporate greenwash. Journal of Business Ethics, 118, 747-757.

Lyon, T. P., \& Shimshack, J. P. (2015). Environmental disclosure: Evidence from Newsweek's Green companies rankings. Business \& Society, 54, 632-675.

Marette, S., Messéan, A., \& Millet, G. (2012). Consumers' willingness to pay for eco-friendly apples under different labels: Evidences from a lab experiment. Food Policy, 37, 151-161.

Massengill, R. P. (2013). Wal-Mart wars: Moral populism in the twenty-first century. New York: NYU Press.

Mathiason, N. (2006, March 19). Coke "drinks India dry." The Guardian. Retrieved from https://www .theguardian.com/money/2006/mar/19/business.india1

McWilliams, A., Siegel, D. S., \& Wright, P. M. (2006). Corporate social responsibility: Strategic implications. Journal of Management Studies, 43, 1-18.

Menges, R., Schroeder, C., \& Traub, S. (2005). Altruism, warm glow and the willingness-to-donate for green electricity: An artefactual field experiment. Environmental \& Resource Economics, 31, 431-458.

Mullen, E., \& Monin, B. (2016). Consistency versus licensing effects of past moral behavior. Annual Review of Psychology, 67, 363-385.

Newman, B. J., \& Bartels, B. L. (2011). Politics at the checkout line. Political Research Quarterly, 64, 803-817. 
Norman, A. (2004). The case against Wal-Mart. Atlantic City, NJ: Raphel Marketing.

Obach, B. K. (2015). Organic struggle: The movement for sustainable agriculture in the United States. Cambridge: MIT Press.

Plambeck, E., \& Denend, L. (2008, Spring). The greening of Wal-Mart. Stanford Social Innovation Review. Retrieved from https://ssir.org/articles/entry/the_greening_of_wal_mart

Potts, J., Lynch, M., Wilkings, A., Cunningham, M., \& Voora, V. (2014). The State of Sustainability Initiatives Review 2014. Retrieved from https://www.iisd.org/pdf/2014/ssi_2014.pdf

Poulsen, R. T., Ponte, S., \& Lister, J. (2016). Buyer-driven greening? Cargo-owners and environmental upgrading in maritime shipping. Geoforum, 68, 57-68.

Powers, N., Blackman, A., Lyon, T. P., \& Narain, U. (2011). Does disclosure reduce pollution? Evidence from India's Green Rating Project. Environmental \& Resource Economics, 50, 131-155.

Prag, A., Lyon, T. P., \& Russillo, A. (2016). Multiplication of Environmental Labelling and Information Schemes (ELIS): Implications for environment and trade. Paris, France: OECD.

Sörqvist, P., Hedblom, D., Holmgren, M., Haga, A., Langeborg, L., Nöstl, A., \& Kågström, J. (2013). Who needs cream and sugar when there is eco-labeling? Taste and willingness to pay for "eco-friendly" coffee. PLoS ONE, 8(12), e80719. doi:10.1371/journal.pone.0080719

Starobin, S., \& Weinthal, E. (2010). The search for credible information in social and environmental global governance: The Kosher label. Business and Politics, 12, 1-35.

Steinhorst, J., Klöckner, C. A., \& Matthies, E. (2015). Saving electricity: For the money or the environment? Risks of limiting pro-environmental spillover when using monetary framing. Journal of Environmental Psychology, 43, 125-135.

Tayleur, C., Balmford, A., Buchanan, G. M., Butchart, S. H. M., Ducharme, H., Green, R. E., . . P Phalan, B. (2017). Global coverage of agricultural sustainability standards, and their role in conserving biodiversity. Conservation Letters, 10, 610-618.

Teisl, M. F., Roe, B., \& Hicks, R. L. (2002). Can eco-labels tune a market? Evidence from dolphin-safe labeling. Journal of Environmental Economics and Management, 43, 339-359.

Teisl, M. F., Rubin, J., \& Noblet, C. L. (2008). Non-dirty dancing? Interactions between eco-labels and consumers. Journal of Economic Psychology, 29, 140-159.

Thauer, C. R. (2014). Managerial sources of corporate social responsibility. Cambridge, England: Cambridge University Press.

The Forum for Sustainable and Responsible Investment. (2016). Sustainable and impact investing in the United States: An overview. Retrieved from http://www.ussif.org/files/Infographics/Overview\%20 Infographic.pdf

Thøgersen, J., \& Noblet, C. (2012). Does green consumerism increase the acceptance of wind power? Energy Policy, 51, 854-862.

Tiefenbeck, V., Staake, T., Roth, K., \& Sachs, O. (2013). For better or for worse? Empirical evidence of moral licensing in a behavioral energy conservation campaign. Energy Policy, 57, 160-171.

Truelove, H. B., Carrico, A. R., Weber, E. U., Raimi, K. T., \& Vandenbergh, M. P. (2014). Positive and negative spillover of pro-environmental behavior: An integrative review and theoretical framework. Global Environmental Change, 29, 127-138.

Tully, S. M., \& Winer, R. S. (2014). The role of the beneficiary in willingness to pay for socially responsible products: A meta-analysis. Journal of Retailing, 90, 255-274.

USDA Economic Research Service. (2013). Organic production. Retrieved from http://www.ers.usda.gov /data-products/organic-production.aspx

van der Ven, H. (2014). Socializing the C-suite: Why some big-box retailers are "greener" than others. Business and Politics, 16, 31-63.

van der Ven, H. (2015). Correlates of rigorous and credible transnational governance: A cross-sectoral analysis of best practice compliance in eco-labeling. Regulation \& Governance, 9, 276-293.

van der Ven, H. (2019). Beyond greenwash? Explaining credibility in transnational eco-labeling. New York, NY: Oxford University Press.

van der Ven, H. (in press). Private accountability in global supply chains. In S. Park \& T. Kramarz (Eds.), The paradox of accountability in global environmental governance. Cambridge: MIT Press.

Walmart. (2007). Wal-Mart launches the live better index with first focus on the environment. Retrieved from https://corporate.walmart.com/_news_/news-archive/2007/04/17/wal-mart-launches-the-live -better-index-with-first-focus-on-the-environment 
Wendt, A. (1994). Collective identity formation and the international state. American Political Science Review, 88, 384-396.

Werther, W. B., Jr., \& Chandler, D. (2005). Strategic corporate social responsibility as global brand insurance. Business Horizons, 48, 317-324.

Willis, M. M., \& Schor, J. B. (2012). Does changing a light bulb lead to changing the world? Political action and the conscious consumer. ANNALS of the American Academy of Political and Social Science, 644, 160-190.

Zhou, J., Liu, Q., Mao, R., \& Yu, X. (2017). Habit spillovers or induced awareness: Willingness to pay for eco-labels of rice in China. Food Policy, 71, 62-73.

\section{Author Biographies}

Graham Bullock is an associate professor of Political Science and Environmental Studies at Davidson College. His first book, Green Grades: Can Information Save the Earth, was published by MIT Press in 2017.

Hamish van der Ven is an assistant professor in the School of Environment and the Department of Political Science at McGill University. His first book - Beyond Greenwash? Explaining Credibility in Transnational Eco-Labeling - was published in 2019 by Oxford University Press. 